\title{
Knowledge of obstetric danger signs and associated factors among pregnant women attending antenatal care at health facilities of Yirgacheffe town, Gedeo zone, Southern Ethiopia
}

Desalegn Tsegaw Hibstu ${ }^{1 *}$ and Yadeshi Demisse Siyoum²

\begin{abstract}
Background: Obstetric danger signs are not the literal obstetric complications, merely symptoms that are well named by non-clinical personnel. The identification of these danger signs and its relation with complications during pregnancy would increase the capacity of women, their partners and families to seek for timely health care, following the appropriate steps to insure a safe birth and post-partum. The aim of this study was to assess the knowledge of obstetric danger signs and associated factors among pregnant women attending antenatal care in Yirgacheffe town, Gedeo zone, Southern Ethiopia.

Method: Institutional-based cross-sectional study was conducted from March 15-April 15, 2016. Data on pregnant women were collected using a pre-tested and interviewer administered structured questionnaire from 342 women using systematic random sampling technique. Bivariate and multivariate logistic regression was performed using SPSS version 20.0 software.

Result: A total of $342(90 \%)$ pregnant women were included in the study. The level of obstetric knowledge of danger signs was $21.9 \%$ (95\% Cl: 20.2-55.65\%). Maternal education ( $\mathrm{OOR}=0.26, \mathrm{Cl}: 0.08,0.88$ ), paternal education $(A O R=0.13, \mathrm{Cl} ; 0.04,04)$ and time taken to reach health facilities on foot $(\mathrm{AOR}=0.06, \mathrm{Cl}: 0.02,0.17)$ were negatively associated factors while maternal age ( $A O R=3.68, \mathrm{Cl}: 1.30,10.46)$, paternal occupation ( $A O R=4.65, \mathrm{Cl}: 1.82,11.87)$, place of residence $(A O R=2.61, \mathrm{Cl}: 1.35,5.04)$ were positively associated factors with knowledge of obstetric danger signs.

Conclusion: Maternal and paternal education, maternal age, paternal occupation, place of residence and time taken to reach health facility on foot were the main factors for knowledge of obstetric danger signs. Increasing knowledge of key danger signs, creating and promoting income generating mechanisms need to be continuously done at the health facility and the community as it makes ready women and their families for prompt and appropriate decisions and measures in case of obstetric danger signs.
\end{abstract}

Keywords: Obstetric danger signs, Knowledge, Yirgacheffe, Ethiopia

\footnotetext{
* Correspondence: desuethiopia@yahoo.com

${ }^{1}$ Department of Reproductive Health, Hawassa University, College of

Medicine and Health Sciences, School of Public and Environmental Health,

Hawassa, Ethiopia

Full list of author information is available at the end of the article
} 


\section{Background}

Women worldwide get pregnant, and about $10 \%$ of them will potentially develop complications that will demand experienced/skilled obstetric care to avert death or life threatening problems [1]. It has also been attested that every day about 14,000 women lose their lives as a result of complications from pregnancy and childbirth [2].

In many developing nations including Ethiopia, maternal mortality yet remains a significant burden and therefore change towards Millennium Development Goal (MDG) five has been particularly disregarded [1]. In developing countries, maternal mortality ratio (MMR) is 15 times higher compared to developed countries. Africa, in particular Sub Saharan countries suffered from the highest MMR at 500 maternal deaths per 100,000 live births [3].

A systematic analysis towards the progress of Millennium Development Goal 5 showed that more than $50 \%$ of all maternal deaths in 2008 were in only six countries (India, Nigeria, Pakistan, Afghanistan, Ethiopia, and the Democratic Republic of the Congo) [4]. The magnitude of maternal mortality and morbidity in Ethiopia are among the highest in the globe. Ethiopian demography and health survey (EDHS) reports from 2005 and 2011 showed that MMR was 673 and 676 per 100,000 live births, respectively $[5,6]$.

The danger signs are not the literal obstetric complications, merely symptoms that are well named by nonclinical personnel. The most frequently occurring danger signs during pregnancy include severe vaginal bleeding, swollen hands/face and blurred vision. The fundamental danger signs during labor and childbirth include severe vaginal bleeding, pro-longed labor, convulsions, and retained placenta. Danger signs during the postpartum period include severe bleeding following childbirth, loss of consciousness after childbirth, and fever [7, 8]. The identification of these danger signs and its relation with complications during pregnancy would increase the capacity of women, their partners and families to seek for timely health care, following the appropriate steps to insure a safe birth and post-partum [9]. One study in Ethiopia by 'Hailu M., et al. [10] concluded that timely recognition of these danger signs is central to the survival of women.

Approximately $80 \%$ of maternal deaths globally occurred due to direct obstetric complications (postpartum severe bleeding, infections following delivery, unsafe induced abortion, and hypertensive disorders in pregnancy and obstructed labour). Hemorrhage solely accounts for one third of all maternal deaths in Africa; still many of these deaths are avoidable. Indirect causes such as malaria, diabetes, hepatitis, anemia and other cardiovascular disorders aggravated by pregnancy can also lead to maternal death $[11,4]$.

In recent decades, numerous strategies have been carried out for the betterment of maternal health throughout the world [12], the basic aim of antenatal care is to identify the main symptoms and prevent the appearance of life threatening complications during pregnancy, thus addressing the pregnant women's information needs and providing advice and reassurance [13].

The national reproductive strategy of Ethiopia has given stress to maternal and newborn health to cut down the increased maternal and neonatal mortality. Two of the strategies are empowering women, men, families, and communities to recognize pregnancy-related risks, and to take responsibility for developing and implementing appropriate responses to them and creating an environment supportive to safe motherhood and newborn health [14].

The Federal Ministry of Health (FMOH), reproductive health department and health bureaus of respective regions in Ethiopia have made cooperative effort to promote knowledge of women about obstetric danger signs to decrease maternal mortality to an acceptable level. They have been applying multiple approaches at local and national levels to have better access to health care information across the country including activities as training of health care providers and health extension workers, organizing civil societies, supporting women to women's associations (such as Health development army, women's networks, etc.), increasing access to health facilities and allocating health resources equitably among rural and urban areas [15].

Though, big emphasis is given by the national strategy to raise knowledge of obstetric danger signs, there is little information about the current level of knowledge and the determining factors in Ethiopia [10]. Therefore, this study was carried out to determine the level of knowledge about obstetric danger signs and associated factors among pregnant women attending antenatal care in Yirgacheffe town, Gedeo zone, Southern Nation, Nationalities and People Region (SNNPR), Ethiopia.

\section{Methods \\ Study setting and period}

The study was conducted in Yirgacheffe town, Gedeo zone, from March 15-April 15, 2016, which is known for producing coffee as an important cash crop globally. It is located in SNNPR, Ethiopia at a distance of $395 \mathrm{~km}$ from Addis Ababa, capital city of Ethiopia and $125 \mathrm{~km}$ from Hawassa, capital city of SNNPR.

The town has two health centers providing preventive, promotive, and curative and rehabilitation services for the community of the town and the surrounding community. The health center provides health education on regular basis for women attending antenatal visits on danger signs that occur during pregnancy, child birth and postpartum period. It also provides different laboratory tests including hemoglobin, urinalysis, sexually 
transmitted diseases and appropriate physical examination during their antenatal visits.

\section{Study design and populations}

An institutional-based quantitative cross-sectional study was employed. The source population for this study was all pregnant women found in Yirgacheffe town and the study populations were pregnant women attending ante natal care at health facilities of the town.

\section{Sample size and sampling procedure}

Sample size was determined using single population proportion formula by considering the following assumption: 95\% confidence level, 5\% margin of error and proportion of knowledge about obstetric danger signs 45.9\% [10].

$$
n=\frac{(z \alpha / 2)^{2} p(1-p)}{=}=\frac{(1.96)^{2} \times 0.459(0.541)}{d^{2}}=\frac{3.84 \times 0.248}{(0.05)^{2}}=381
$$

Study participants were selected by systematic random sampling technique with an interval of three where the interval constant was obtained by dividing the total ANC attendants to the sample size from their antenatal care registration book.

\section{Operational definitions}

Knowledge of women about obstetric danger signs were measured by the total number of correct spontaneous answers to 9 items on knowledge of pregnancy danger signs and 7 items on knowledge of labor and childbirth danger signs and 7 items on knowledge of postpartum danger signs with a minimum score of 0 and maximum of 9 .

Accordingly, three categories were developed for pregnancy, labor/childbirth and post-partum. Knowledgeable on key danger signs of pregnancy: a woman was considered as knowledgeable when she mentioned at least three key danger signs for pregnancy spontaneously. Knowledgeable on key danger signs of labor/childbirth: a woman was considered as knowledgeable when she mentioned at least three key danger signs for labor/childbirth spontaneously. Knowledgeable on key danger signs of post-partum: a woman was considered knowledgeable if when she mentioned at least the three key danger signs for post-partum spontaneously [16]. The dependent variable was later dichotomized as knowledgeable and not-knowledgeable.

\section{Data collection tool and procedure}

Pre-tested and interviewer-administered structured questionnaires were used. Fifth year female medical students were recruited to collect the data. The questionnaire was prepared in English language and translated to Amharic (local language) and translated back to English to maintain the consistence of the data. Training was given to data collectors for two days. Two master's degree holders supervised the overall data collection and check for filled questionnaire for consistency and completeness. During data collection, questionnaires were reviewed and checked for completeness and relevance by the principal investigators and the supervisors.

\section{Data processing and analysis}

After data collection, data were edited and cleaned before data analysis, each questionnaire was checked for completeness and code was given before data entry. Data was cleaned and entered into computer by using EPI Info version 3.5.3 and the analysis was done using SPSS version 20.0 .

Frequency, percentage and descriptive summaries were used to describe the study variable using univarite analysis. Logistic regression was carried out to identify factors associated with knowledge of obstetric danger signs. Variables with $p$-value $\leq 0.2$ in the bivariate analysis were selected as candidate variables for multivariate logistic regression analysis to control the effect of confounders. Adjusted odds ratios with their $95 \%$ confidence intervals and $p$-value of less than 0.05 were considered to have significant association between the outcome and the explanatory variables. The model fitness was checked using Hosmer and Lemeshow.

\section{Results}

\section{Socio demographic and economic characteristics}

A total of 342 pregnant women were included in the study with a response rate of $90 \%$. The minimum and the maximum age of the respondents were 16 years and 43 years, respectively. The mean age of the study subjects was 26.2 years $( \pm 6.2$, standard deviation $(\mathrm{SD}))$. One hundred nineteen (34.8\%) study subjects were found in the age group 15-24 years.

Almost half $174(50.9 \%)$ of the respondents were protestant by religion followed by orthodox 106 (31\%), and 198 (57.9\%) were Gedeo by ethnicity. Of the total study participants $333(97.4 \%)$ were married with average family size of $4.23( \pm 1.846 \mathrm{SD})$. Nearly three among four study subjects, 252 (73.7\%) decided health service utilization by themselves and $52(15.2 \%)$ were leaders in the family (Table 1).

Concerning education status, one among five, 69 (20.2\%) women attended secondary and above school, and 127 (37.1\%) of their partners/husbands attended secondary and above school. Almost seven among ten pregnant women $(67.5 \%)$ were house wife by occupation and $87(25.4 \%)$ of their counterpart were governmental employed. One hundred four study participants (30.4\%) were living in rural areas (Table 1). 
Table 1 Socio demographic, socio economic and reproductive history characteristics of the study subjects, Yirgacheffe town, Gedeo zone, Southern Ethiopia, 2016

\begin{tabular}{lll}
\hline Variables & Frequency & Percentage \\
\hline Age & & \\
$15-24$ & 119 & 34.8 \\
$25-34$ & 166 & 48.5 \\
$>=35$ & 57 & 16.7
\end{tabular}

Religion

$\begin{array}{ll}\text { Protestant } & 174 \\ \text { Orthodox } & 106 \\ \text { Catholic } & 20 \\ \text { Muslim } & 42 \\ \text { Ethnicity } & \end{array}$

Gedeo

Guraghe

Siliti

Kembata

Sidama

Wolaita

Marital status

Single

Married

Family size

$$
\begin{aligned}
& <=4 \\
& >4
\end{aligned}
$$

Role in the family

Leaders

Members

Decision maker about service utilization

Self
Other person
Maternal education

Unable to read and write

Read and write(No formal education)

Primary education

Secondary and above

Parental education

Unable to read and write

Read and write(No formal education)

Primary education

Secondary and above

Maternal occupation

Housewife

Merchant
Table 1 Socio demographic, socio economic and reproductive history characteristics of the study subjects, Yirgacheffe town,

\begin{tabular}{|c|c|c|}
\hline \multicolumn{3}{|l|}{ Paternal Occupation } \\
\hline Governmental employed & 87 & 25.4 \\
\hline Farmer & 96 & 28.1 \\
\hline Merchant & 145 & 42.4 \\
\hline Daily laborer & 14 & 4.1 \\
\hline \multicolumn{3}{|l|}{ Monthly Income } \\
\hline$<1000$ birr & 104 & 30.4 \\
\hline 1001-2000 birr & 107 & 31.3 \\
\hline 2001-3000 birr & 58 & 17.0 \\
\hline$>30,000$ birr & 73 & 21.3 \\
\hline \multicolumn{3}{|l|}{ Place of Residence } \\
\hline Urban & 203 & 59.4 \\
\hline Rural & 139 & 40.6 \\
\hline \multicolumn{3}{|l|}{ Duration of pregnancy } \\
\hline First trimester & 17 & 5.0 \\
\hline Second trimester & 134 & 39.2 \\
\hline Third trimester & 191 & 55.8 \\
\hline \multicolumn{3}{|l|}{ Age at first pregnancy } \\
\hline $15-24$ years & 326 & 95.3 \\
\hline$>24$ years & 16 & 4.7 \\
\hline \multicolumn{3}{|l|}{ Number of pregnancy } \\
\hline 1 & 85 & 24.9 \\
\hline$>=2$ & 257 & 75.1 \\
\hline \multicolumn{3}{|l|}{ Number of parity } \\
\hline $1-4$ & 232 & 67.8 \\
\hline$>4$ & 110 & 32.2 \\
\hline \multicolumn{3}{|l|}{ Number of ANC follow up } \\
\hline 1 & 109 & 31.9 \\
\hline 2 & 82 & 24.0 \\
\hline 3 & 84 & 24.6 \\
\hline 4 & 67 & 19.5 \\
\hline \multicolumn{3}{|c|}{ Time taken to health facility(on foot) } \\
\hline$<30 \min$ & 309 & 90.4 \\
\hline$\geq 30 \mathrm{~min}$ & 33 & 9.6 \\
\hline
\end{tabular}
Gedeo zone, Southern Ethiopia, 2016 (Continued)

\section{Reproductive history}

Three hundred twenty six (95.3\%) of the study participants were in the age group 15-24 years old during their first pregnancy. Three among four, 257 (75.1\%) had history of two or above pregnancy. Three among five 203 (59.4\%) study participants delivered their last child in a health facility. The majority, 309 (90.4\%) of participants reported that below thirty minute is required to reach the health institution. One hundred nine (31.9\%) and 67 (19.5\%) of the study participants had their first and 
fourth ANC visits during their pregnancy period, respectively (Table 1 ).

\section{Knowledge of obstetric danger signs}

The overall knowledge of study participants regarding obstetric danger signs was $21.9 \%$ (95\% CI: $20.2-55.65 \%$ ). Almost half of the study subjects, 168 (49.1\%) were found to be knowledgeable about danger signs during pregnancy. It was also found that 181 (52.9\%) participants were knowledgeable about danger signs during child birth. One hundred fifty three, 153 (44.7\%) study subjects were knowledgeable about danger signs during postpartum period. Severe vaginal bleeding was the most frequently known danger sign mentioned by study participants during pregnancy 258 (75.4\%), 252 (73.7\%), labor and child birth, and $158(46.2 \%)$ at postpartum period (Table 2).

\section{Associated factors with knowledge of obstetric danger signs}

In the multivariate analysis maternal age, maternal and paternal education, paternal occupation, time taken on foot to the health facility and place of residence were significantly associated with knowledge of obstetric danger signs.

The study demonstrated that women in the age group $25-34$ years old were $3.5(\mathrm{AOR}=3.68, \mathrm{CI}: 1.30,10.46)$ times more likely to be knowledgeable of obstetric danger signs in relation with women who were 35 years old and above.

Women who can read and write but without formal education was $75 \%(\mathrm{AOR}=0.26$, CI: 0. 08, 0.88) less likely to be knowledgeable about obstetric danger signs compared to women who attended secondary and above education.

It was also observed that the probability of having knowledge of obstetric danger signs decreased almost by $90 \%(\mathrm{AOR}=0.13, \mathrm{CI} ; 0.04,0.40)$ among women whose partners/husbands did not read and write, than those whose literacy status was secondary and above education.

Another important predictor was parental/husband occupation and place of residence. The chance of having knowledge of obstetric danger signs was 5 times $(\mathrm{AOR}=4.65, \mathrm{CI}: 1.82,11.87)$ higher among women whose husbands were merchant by occupation compared with governmental employed. Women living in urban areas were 3 times (AOR $=2.61, \mathrm{CI}: 1.35,5.04$ ) more likely to have knowledge of obstetric danger signs compared to those living in rural areas.

On the other hand, knowledge of obstetric danger signs was $95 \%(\mathrm{AOR}=0.06, \mathrm{CI}: 0.02,0.17)$ less likely among women who travelled on foot more than $30 \mathrm{~min}$ to health facilities for health service utilization (Table 3).

\section{Discussion}

Every minute, a woman dies due to causes related to pregnancy, childbirth and postnatal period. These causes are avoidable if women with complications are able to identify and seek appropriate emergency obstetric care, which makes a difference between life and death. Thus, this study had tried to determine the level of knowledge about obstetric danger signs and associated factors among pregnant women attending antenatal care in Yirgacheffe town, Gedeo zone, Southern Nation, Nationalities and People Region, Ethiopia.

In this study, it was revealed that the overall knowledge of obstetric danger signs was $21.9 \%$. This finding is congruent with the studies conducted in Ethiopia: Alettawondo (30.9\%) and Arba Minch (24.1\%), SNNPR [10, 16]; Debre-Birhan (38.6\%), Amhara Region [17].

On the other hand, in this study about $75 \%$ of the study subjects explained that vaginal bleeding as danger sign during pregnancy which was higher than the findings in Burkina Faso (39.4\%) [18], Guatemala (31.0\%) [19] and Tigray, Ethiopia (49.1\%) [20]. This variation might be due to socio-cultural difference and difference in implementation of relevant health intervention programs such as provision of antenatal care and delivery services. The finding of the study also indicated that half, 168 (49.1\%) of the respondents were knowledgeable about the danger signs of pregnancy which is inconsistent with findings in Tigray, Ethiopia and India [20, 21], respectively.

Significant association was observed concerning maternal age. It was figured out that knowledge of obstetric danger signs was more likely to increase among women with the age group 25-34 years old. This finding is congruent with studies conducted in Ethiopia, Tanzania, Enugu State, Nigeria and South East Nigeria, [16, 22-24], respectively. It might be explained as elder women not only own better knowledge of obstetric danger signs in this age group but also they are psychologically and physically ready to accept information on danger signs.

Maternal and paternal/husband education were identified a predictor for knowledge of obstetric danger signs. It was indicated that the level of obstetric danger signs knowledge was increased among women and husbands attended secondary and above education compared with those with no education. This study is in line with other studies [16, 20, 23, 25-27]. This might be explained by the fact that there is no question that educated women can have better information and care for themselves. Education provides better health knowledge, improves the effectiveness of health behavior and enables to take prompt measures when the danger signs arise.

The place of residence was also found as a determinant of knowledge of obstetric danger signs. The study found that obstetric danger signs knowledge of women 
Table 2 Knowledge of obstetric danger signs during pregnancy and post-partum period in Yirgacheffe town, Gedeo zone, Southern Ethiopia, 2016

\begin{tabular}{|c|c|c|c|c|c|c|}
\hline \multirow[t]{3}{*}{ Characteristics } & \multicolumn{6}{|c|}{ Knowledge of danger signs during: } \\
\hline & \multicolumn{2}{|l|}{ Pregnancy } & \multicolumn{2}{|c|}{ Labor and child birth } & \multicolumn{2}{|l|}{ Post-partum } \\
\hline & Frequency & $\overline{\text { Percentage }}$ & Frequency & $\overline{\text { Percentage }}$ & Frequency & Percentage \\
\hline \multicolumn{7}{|c|}{ Vaginal bleeding } \\
\hline No & 84 & 24.6 & 90 & 26.3 & 184 & 53.8 \\
\hline Yes & 258 & 75.4 & 252 & 73.7 & 158 & 46.2 \\
\hline \multicolumn{7}{|c|}{ Difficulty of breathing } \\
\hline No & 317 & 92.7 & NA & NA & 261 & 76.3 \\
\hline Yes & 25 & 7.3 & NA & NA & 81 & 23.7 \\
\hline \multicolumn{7}{|c|}{ Loss of consciousness } \\
\hline No & 314 & 91.8 & 317 & 92.7 & 280 & 81.9 \\
\hline yes & 28 & 8.2 & 25 & 7.3 & 62 & 18.1 \\
\hline \multicolumn{7}{|l|}{ High fever } \\
\hline No & 298 & 87.1 & 272 & 79.5 & NA & NA \\
\hline Yes & 44 & 12.9 & 70 & 20.5 & NA & NA \\
\hline \multicolumn{7}{|c|}{ Severe Headache } \\
\hline No & 237 & 69.3 & 261 & 76.3 & 265 & 77.5 \\
\hline Yes & 105 & 30.7 & 81 & 23.7 & 77 & 22.5 \\
\hline \multicolumn{7}{|c|}{ Severe abdominal pain } \\
\hline No & 182 & 53.2 & NA & NA & NA & NA \\
\hline Yes & 160 & 46.8 & NA & NA & NA & NA \\
\hline \multicolumn{7}{|l|}{ Blurred vision } \\
\hline No & 224 & 65.5 & NA & NA & 255 & 74.6 \\
\hline Yes & 118 & 34.5 & NA & NA & 87 & 25.4 \\
\hline \multicolumn{7}{|l|}{ Convulsion } \\
\hline No & 329 & 96.2 & 293 & 85.7 & 332 & 97.1 \\
\hline Yes & 13 & 3.8 & 49 & 14.3 & 10 & 2.9 \\
\hline \multicolumn{7}{|c|}{ Swollen Hand/face } \\
\hline No & 279 & 81.6 & NA & NA & 293 & 85.7 \\
\hline Yes & 63 & 18.4 & NA & NA & 49 & 14.3 \\
\hline \multicolumn{7}{|c|}{ Vaginal discharge } \\
\hline No & NA & NA & NA & NA & 281 & 82.2 \\
\hline Yes & NA & NA & NA & NA & 61 & 17.8 \\
\hline \multicolumn{7}{|c|}{ Mal-position/presentation } \\
\hline No & NA & NA & 235 & 68.7 & NA & NA \\
\hline Yes & NA & NA & 107 & 31.3 & NA & NA \\
\hline \multicolumn{7}{|c|}{ Retained placenta } \\
\hline No & NA & NA & 230 & 67.3 & NA & NA \\
\hline Yes & NA & NA & 112 & 32.7 & NA & NA \\
\hline \multicolumn{7}{|c|}{ Labor lasting $>12 \mathrm{~h}$} \\
\hline No & NA & NA & 194 & 56.7 & NA & NA \\
\hline Yes & NA & NA & 148 & 43.3 & NA & NA \\
\hline
\end{tabular}

$N A$ indicates that the specific danger sign was not asked 
Table 3 Factors associated with knowledge of obstetric danger signs in Yirgacheffe town, Gedeo zone, Southern Ethiopia, 2016

\begin{tabular}{|c|c|c|c|c|c|}
\hline \multirow[t]{2}{*}{ Variables } & \multicolumn{2}{|c|}{ Knowledge of obstetric danger signs } & \multirow[t]{2}{*}{ COR $(95 \% \mathrm{Cl})$} & \multirow[t]{2}{*}{ AOR $(95 \% \mathrm{Cl})$} & \multirow[t]{2}{*}{$P$-value } \\
\hline & Not knowledgeable & Knowledgeable & & & \\
\hline \multicolumn{6}{|l|}{ Maternal age } \\
\hline $15-24$ & 102 & 17 & $1.02(0.41,2.53)$ & $1.33(0.42,4.17)$ & 0.230 \\
\hline $25-34$ & 116 & 50 & $2.64(1.17,5.98)$ & $3.68(1.30,10.46)$ & 0.001 \\
\hline$>=35$ & 49 & 8 & 1 & & \\
\hline \multicolumn{6}{|l|}{ Maternal education } \\
\hline Unable to read and write & 89 & 20 & $0.48(0.24,0.97)$ & $0.33(0.10,1.07)$ & 0.433 \\
\hline Read and write(no formal education) & 74 & 10 & $0.29(0.13,0.66)$ & $0.26(0.08,0.88)$ & 0.010 \\
\hline Primary education & 57 & 23 & $0.86(0.43,1.74)$ & $0.79(0.30,2.09)$ & 0.445 \\
\hline Secondary and above & 47 & 22 & 1 & 1 & \\
\hline \multicolumn{6}{|l|}{ Paternal education } \\
\hline Unable to read and write & 30 & 7 & $0.46(0.19,1.12)$ & $0.13(0.04,0.40)$ & 0.006 \\
\hline Read and write(no formal education) & 41 & 8 & $0.38(0.16-0.89)$ & $0.08(0.02,0.24)$ & 0.045 \\
\hline Primary education & 112 & 17 & $0.30(0.16-0.56)$ & $0.10(0.04,0.25)$ & 0.005 \\
\hline Secondary and above & 84 & 43 & 1 & 1 & \\
\hline \multicolumn{6}{|l|}{ Paternal occupation } \\
\hline Governmental employed & 71 & 16 & 1 & 1 & \\
\hline Farmer & 75 & 21 & $1.24(0.60,2.57)$ & $0.05(0.01,0.26)$ & 0.016 \\
\hline Merchant & 113 & 32 & $1.26(1.64,2.46)$ & $4.65(1.82,11.87)$ & 0.001 \\
\hline Daily laborer & 8 & 6 & $3.33(0.02,10.9)$ & $0.28(0.06,1.32)$ & 0.245 \\
\hline \multicolumn{6}{|l|}{ Place of residence } \\
\hline Urban & 170 & 33 & $2.23(1.33,3.75)$ & $2.61(1.35,5.04)$ & 0.000 \\
\hline Rural & 97 & 42 & 1 & 1 & \\
\hline \multicolumn{6}{|l|}{ Distance to Health facility on foot } \\
\hline$<30 \min$ & 12 & 21 & 1 & 1 & \\
\hline$\geq 30$ & 255 & 54 & $0.12(0.06,0.26)$ & $0.06(0.02,0.17)$ & 0.000 \\
\hline
\end{tabular}

Hosmer and Lemeshow for model fitness is 0.876

were more likely to increase among women living in urban residence in comparison with rural areas. This finding was supported by the findings in Ethiopia: Erer district, Somali region and Goba district region [26-28] and a study in Southeast Nigeria [24]. This is probably because urban areas are exposed to different health care services including higher coverage with health information dissemination.

On the other hand, probably because better access to health facility and health information due to increased access to health facilities, it was pointed out that knowledge of obstetric danger signs was more likely to increase among women who travelled less than thirty minutes on foot for health service utilization. This study was in agreement with the findings in other areas [24, 27].

The paternal/husband occupational status in this study was significantly associated with maternal knowledge of obstetric danger signs. The probability of obstetric danger signs knowledge was highest among women whose husbands were merchants by occupation. This study is agreed with the finding in Nigeria [24]. This might happen because merchant fathers would have a positive outcome in knowledge of obstetric danger signs by increasing household income and economic status of the family and as a result women might get frequent health institution contact for antenatal care, delivery and health information about obstetric danger signs.

While interpreting the findings of this study, scholars need to take into consideration the following limitations. First, the cross sectional nature of the data had made impossible to arrive at the causal relation between the different explanatory variables and knowledge of women about obstetric danger signs. Second, an expected proportion of knowledge about obstetric danger signs of the women in the study $(N=381)$ was not reached, as only 342 pregnant women were included with a response rate of $90 \%$. Third, as the study is based on a sample of all pregnant women attending antenatal care, possible selection 
bias needs to be considered since it did not address the main characteristic of the general population in the study.

\section{Conclusions}

In general, in this study, the level of obstetric danger signs knowledge was low. Maternal and husband education, paternal occupational, maternal age, place of residence and time taken to reach health facility on foot were identified as the significant factors for knowledge of obstetric danger signs among pregnant women in Yirgacheffe town, Gedeo zone, Southern Ethiopia.

Increasing knowledge or awareness of key obstetric danger signs need to be given focus as it makes women and their families ready for prompt and appropriate decisions and measures in case of obstetric danger signs among pregnant women. Health education dissemination strategies on obstetric danger signs and creating and promoting income generating mechanisms need to be continuously done at the health facility and community.

\section{Abbreviations}

ANC: Ante natal care; AOR: Adjusted odd ratio; Cl: Confidence interval: COR: Crude odd ratio; EDHS: Ethiopian demography and health survey; FMOH: Federal Ministry of Health; MDG: Millennium development goal; MMR: Maternal mortality ratio; SD: Standard deviation; SNNPR: Southern Nation Nationalities and People Region; SPSS: Statistical package for social science; UN: United Nations; WHO: World Health Organization

\section{Acknowledgements}

We are thankful to Gedeo zone health department and Yirgacheffe town health office for easing the data collection work. We would also like to extend our profound gratitude to the study subjects without their consent and the provision of the demanded information this research work would not have been real.

\section{Funding}

This research work was financed by Hawassa University, College of Medicine and Health Sciences, Ethiopia. The funder had no role in study design, data collection and analysis, decision to publish, or preparation of the manuscript.

\section{Availability of data and materials}

The data that support the findings of this study will be available from the corresponding author upon reasonable request in the form of statistical package for social sciences (SPSS) spread sheet.

\section{Authors' contributions}

DTH took part in planning the study, monitoring data collection process, analyzes the data and writing the manuscript. YDS participated in designing the study, supervising data collection process and writing the manuscript. Both authors read and approved the final manuscript.

\section{Competing interests}

The authors declare that they have no competing interests.

\section{Consent for publication}

Written informed consent was taken from study participants for publication explaining: the objective and benefit of the finding of the study and their personal identifiers was not attached.

\section{Ethics approval and consent to participate}

Ethical clearance was obtained from the Institutional Review Board of Hawassa University, College of Medicine and Health Sciences. Official letters was taken from Yirgacheffe town health office. The study participants were informed about the purpose of the study and informed verbal consent was secured. All participants' right to self-determination was respected. The confidentiality and the privacy of the respondents were maintained.

\section{Publisher's Note}

Springer Nature remains neutral with regard to jurisdictional claims in published maps and institutional affiliations.

\section{Author details}

${ }^{1}$ Department of Reproductive Health, Hawassa University, College of Medicine and Health Sciences, School of Public and Environmental Health, Hawassa, Ethiopia. ${ }^{2}$ Department of Public Health, Hawassa University, College of Medicine and Health Sciences, School of Public and Environmental Health, Hawassa, Ethiopia.

Received: 20 August 2016 Accepted: 6 June 2017

Published online: 14 August 2017

\section{References}

1. World Health Organization. Improve the quality of maternal health services. Geneva, Switzerland, WHO. Division of Reproductive Health (Technical Support), 1998; 4 (World Health Day - 7April: Safe motherhood / WHO 98.8). Accessed 14 Aug 2008

2. Donna V, Barbara K. Improving maternal health. e Journal USA. Econ Perspect. 2005:1-7.

3. The Maternal Mortality Estimation Inter-Agency Group, USA. WHO, UNICEF, UNFPA and World Bank estimates. Switzerland: World Health Organization. 2010. Available: http://www.unfpa.org/webdav/site/global/shared/ documents/publications/2012/Trends in maternal_ mortality_A4-1.Pdf.

4. WHO. Trends in maternal mortality: 1990 to 2010, WHO, UNFPA, UNICEF and World Bank. Geneva; WHO; 2012.

5. Central Statistical Agency, Ethiopia. Ethiopia demographic and health survey 2011; 2005. Ethiopia: Central statistical agency.

6. Central Statistical Agency, Ethiopia. Ethiopia demographic and health survey 2011. Ethiopia: Central statistical agency; 2011

7. JHPIEGO. Maternal and neonatal health program. birth preparedness and complication readiness: a matrix of shared responsibilities. JHPIEGO: Maryland; 2004

8. Thaddeus S, Maine D. Too far to walk: maternal mortality in context. Soc Sci Med. 1994;38:1091-110.

9. WHO. Standards for maternal and neonatal care: birth and emergency preparedness in antenatal care: department of making pregnancy safer (MPS). Geneva: World Health Organization; 2006.

10. Hailu M, Gebremariam A, Alemsged F. Knowledge about obstetric danger signs among pregnant women in AlettaWondo district, Sidama zone, Southern Ethiopia. Ethiop J Health Sci. 2010;20(1):25-32.

11. UNICEF. A global overview of maternal mortality. 2010

12. Berg C, Daniel I, Zane S, Bartlett L, eds. Strategies to reduce pregnancyrelated deaths: from identification and review to action. Atlanta, Centers for Disease Control and Prevention; 2001; 45-7. In: Bullough C, Meda N, Makowiecka K, Ronsmans C, Achadi E, Hussein J. Current strategies for the reduction of maternal mortality. BJOG. 2005; 112 (9): 1180-8.

13. National Population Commission (Nigeria) and ICF Macro Nigeria. Nigeria Demographic and Health Survey. Calverton: National Population Commission and ICF/Macro; 2008. p. 2009.

14. Federal Democratic Republic of Ethiopia, Ministry of Health. National reproductive strategy 2006-2015. Addis Ababa: FMOH; 2006.

15. Federal Democratic Republic of Ethiopia, $\mathrm{MOH}$. Health sector development program IV 2010/11-2014/15. Ethiopia: FMOH; 2010.

16. Workineh $Y$, Hailu D, Gultie T, Degefu N, Mihrete M, Shimeles M, et al. Knowledge of obstetric danger signs and its associated factors in Arba Minch town, Ethiopia. Am J of Health Res. 2014;2(5):255-9.

17. Akililu A, Wakgari N, Admasu E, Berta M. Knowledge about danger signs of pregnancy and associated factors among pregnant women in Debre Birhan Town, Central Ethiopia. Sci J Public Health. 2015;3(2):269-73.

18. Baya B, Sangli G, Maiga A. Measuring the effects of behavior change interventions in Burkina Faso with population-based survey results. JHPIEGO: Maryland; 2004

19. Becker F, Yglesias C. Measuring the effects of behavior change and service deliver interventions in Guatemala with population-based survey. JHPIEGO: Maryland, USA; 2004

20. Hailu D, Berhe $\mathrm{H}$. Knowledge about obstetric danger signs and associated factors among mothers in Tsegedie District, Tigray Region, Ethiopia 2013: community based cross-sectional study. PLoS One. 2014:9(2):e83459. doi:10.1371/journal.pone.0083459K1 
21. Agarwal S, Sethi V, Srivastava K, Jha PK, Baqui AH. Birth preparedness and complication readiness among slum women in Indore City, India. J Health Popul Nutr. 2010;28(4):383-91.

22. Pembe AB, Urassa DP, Carlstedt A, Lindmark G, Nystrom L, et al. Rural Tanzanian women's awareness of danger signs of obstetric complications. BMC Pregnancy Childbirth. 2009;26:9-12.

23. Agunwa CC, Nnebue CC, Duru CB, Aniebue PN, Aniebue UU, Ifeadike CO. Knowledge of obstetric danger signs among women of reproductive age in rural communities in Enugu State, Nigeria. Am J Health Res. 2015;3(6):376-80. doi:10.11648/j.ajhr.20150306.20. for maternal age and educational status

24. Ossai EN, Uzochukwu BS. Knowledge of danger signs of pregnancy among clients of maternal health service in urban and rural primary health centres of Southeast Nigeria. J Community Med Health Educ. 2015;5:337. doi:10. 4172/2161-0711.1000337.

25. Dile M, Taddesse D, Gedefaw M, Asmama T. Knowledge of obstetric danger signs and its associated factors in debaytilatgin district, ethiopia: a community based cross sectional study. Gynecol Obstet (Sunnyvale). 2015;5: 315. doi:10.4172/2161-0932.1000315.

26. Maseresha e ta I (2016) Knowledge of obstetric danger signs and associated factors among pregnant women in Erer district, Somali region, Ethiopia 2016: community based cross-sectional study. BMC Pregnancy Childbirth 16:30: DOl: 10.1186/s12905-016-0309-3.

27. Daniel B, Desalegn M. Knowledge of obstetric danger signs among child bearing age women in Goba district, Ethiopia 2013: community based cross-sectional study. BMC Pregnancy Childbirth. 2015;15:77. doi:10.1186/ s12884-015-0508-1.

28. Gedefa A, Zerfu M, Tewodros S, Hinsermu B. Knowledge about danger signs of obstetric complications and associated factors among postnatal mothers of Mechekel District Health Centers, East Gojjam Zone, Northwest Ethiopia, 2014. Hindawi Publishing Corporation Scientifica; 2016. Volume 2016, Article ID 3495416, http://dx.doi.org/10.1155/2016/3495416. maternal and paternal education.

\section{Submit your next manuscript to BioMed Central and we will help you at every step:}

- We accept pre-submission inquiries

- Our selector tool helps you to find the most relevant journal

- We provide round the clock customer support

- Convenient online submission

- Thorough peer review

- Inclusion in PubMed and all major indexing services

- Maximum visibility for your research

Submit your manuscript at www.biomedcentral.com/submit 